\title{
ALGORITMA DECISION TREE C4.5 UNTUK KLASIFIKASI TINGKAT PENGETAHUAN MASYARAKAT TERHADAP PEMANFAATAN BANK SAMPAH DI KABUPATEN BANJARMASIN SELATAN
}

\author{
Agus Setiawan \\ Fakultas Teknologi Informasi,Universitas Islam Kalimantan Muhammad ArsyadAl Banjari Banjarmasin \\ Email:agusteknik08@gmail.com
}

\begin{abstract}
Abstrak
Program Bank Sampah adalah salah satu program kementrian lingkungan hidup. Pembangunan bank sampah ini harus menjadi momentum awal membina kesadaran kolektif masyarakat untuk memulai memilih, mendaur ulang dan memanfaatkan sampah karena sampah mempunyai nilai jual yang cukup baik sehingga pengelolaan sampah yang berwawasan lingkungan menjadi budaya baru di Indonesia (Kementrian lingkungan hidup, 2012). Kelurahan Pemurus Baru adalah wilayah yang padat penduduk dan berdekatan dengan TPS (Tempat Pembuangan Sementara). Ketika peneliti melakukan kunjungan ke lokasi, sebagian masyarakat yang bermukim di wilayah tersebut membuang sampah langsung ke TPS dan hanya sedikit yang memanfaatkan Bank Sampah. Metode yang dilakukan merupakan penerapan metode data mining menggunakan Algoritma Decision Tree C4.5 dari Segi Pengetahuan, Pendidikan dan Usia seseorang. Setelah dilakukan pengujian, hasilnya menunjukkan performance accuracy sebesar 99.34\%. Dengan demikian, masyarakat masih belum atau tidak memanfaatkan bank sampah sehingga perlu di tingkatkan lagi sosialisasi terhadap masyarakat untuk bisa memanfaatkan bank sampah dengan baik.
\end{abstract}

Keywords : Bank Sampah, Data Mining, Decision Tree

\section{PENDAHULUAN}

Program Bank Sampah adalah salah satu program kementrian lingkungan hidup. Pembangunan bank sampah ini harus menjadi momentum awal membina kesadaran kolektif masyarakat untuk memulai memilih, mendaur ulang dan memanfaatkan sampah karena sampah mempunyai nilai jual yang cukup baik sehingga pengelolaan sampah yang berwawasan lingkungan menjadi budaya baru di Indonesia (Kementrian lingkungan hidup, 2015).

Pengelolaan bank sampah di Indonesia bertujuan untuk meningkatkan daur ulang sampah kering dan pembuatan kompos. Hal ini merupakan penerapan dalam manajemen ekosentris yang berpusat pada manusia dan kehidupan secara keseluruhan [1]. Pengelolaan sampah melalui kegiatan Bank sampah pertama kali muncul di Desa Badegan, Bantul, Provinsi DI Yogyakarta pada tahun 2008 yang dikembangkan oleh komunitas pecinta lingkungan [2]. Dalam pengelolaan bank sampah ini tidak terlepas dari adanya suatu organisasi khusus yang dibentuk untuk kemajuan bank sampah. Kartini (2009), menyatakan bahwa "keaktifan dalam berorganisasi merupakan salah satu faktor yang mempengaruhi masyarakat untuk turut berpartisipasi dalam kegiatan bank sampah. [3], juga menyebutkan dalam partisipasi masyarakat yang turut aktif dapat mengurangi beban lingkungan sekitar serta dapat menguntungkan masyarakat dari segi ekonomi”.

Kelurahan Pemurus Baru adalah wilayah yang padat penduduk dan berdekatan dengan TPS (Tempat Pembuangan Sementara). Ketika peneliti melakukan kunjungan ke lokasi, sebagian masyarakat yang bermukim di wilayah tersebut membuang sampah langsung ke TPS dan hanya sedikit yang memanfaatkan Bank sampah.

Kelurahan Pemurus Baru merupakan salah satu Kelurahan yang ada di Kecamatan Banjarmasin Selatan, Kota Banjarmasin yang letaknya di Jalan Prona 1 No. 4 Rt. 16 A.Yani Km.5. Kelurahan ini memiliki jumlah kepala keluarga sebesar 368 jiwa dimana terdapat tiga Rukun Tetangga (RT) yang sudah mendirikan Bank Sampah. Pada tahun 2014, berdasarkan data operasional 2 Bank sampah yang sudah berdiri di Kelurahan Pemurus Baru Banjarmasin Selatan yaitu Bank Sampah Bina Insani RT. 10 dan RT. 29, dan Bank Sampah Gawi Manuntung RT. 19, peran serta masyarakat dalam pengelolaan sampah rumah 
tangga, hanya sebanyak 45 orang atau $12 \%$ dari total jumlah kepala keluarga yang menyetor sampahnya ke bank sampah.

Dari hasil wawancara dengan kader Bank sampah disana, dikatakan bahwa fasilitas dan relasi untuk mendukung pengelolaan sampah rumah tangga skala komunal dapat dikatakan sudah baik. Hal itu ditunjukkan dengan sudah adanya lahan dan bangunan Bank sampah yang memadai, serta kerjasama dengan pihak pengepul, akan tetapi itu semua tidak diikuti dengan baiknya kesadaran dan pengetahuan masyarakat setempat untuk memanfaatkan Bank sampah dalam mengelola sampah rumah tangga di Kelurahan Pemurus Baru.

Dari Permasalahan yang ada di perlukan sebuah penelitian yang dilakukan dengan Penerapan Metode Data Mining Menggunakan Algoritma Decision Tree C4.5 untuk mengetahui tingkat pengetahuan masyarakat terhadap bank sampah.

\section{METODE PENELITIAN}

a. Pengumpulan Data

\section{Tabel 1. Pengumpulan Data Penelitian Bank Sampah}

\begin{tabular}{|c|c|c|c|}
\hline VARIABEL & KETERANGAN & & KATEGORI \\
\hline \multirow{2}{*}{ Y } & \multirow{2}{*}{ status } & 1 & Memanfaatkan \\
\hline & & 2 & Tidak Memanfaatkan \\
\hline \multirow{3}{*}{$\mathrm{X} 1$} & \multirow{3}{*}{ Pengetahuan } & 1 & Baik \\
\hline & & 2 & Sedang \\
\hline & & 3 & Kurang \\
\hline \multirow{4}{*}{$\mathrm{X} 2$} & \multirow{4}{*}{ Pendidikan } & 1 & SD \\
\hline & & 2 & SMP \\
\hline & & 3 & SMA \\
\hline & & 4 & $\mathrm{DIII} / \mathrm{S} 1 / \mathrm{S} 2$ \\
\hline \multirow{4}{*}{ X3 } & \multirow{4}{*}{ USIA } & 1 & $20-30$ Tahun \\
\hline & & 2 & 31 - 40 Tahun \\
\hline & & 3 & 41 - 50 Tahun \\
\hline & & 4 & $>50$ Tahun \\
\hline
\end{tabular}

b. Pengolahan data awal

Pengolahan data merupakan salah satu bagian dari rangkaian kegiatan penelitian setelah kegiatan pengumpulan data dilakukan. Data yang telah terkumpul akan di proses menggunakan Data Mining untuk mengetahui hasil dari varibel tersebut.

c. Eksperimen dan Pengujian
Pada tahap ini dilakukan suatu pengujian menggunakan algoritma decision tree C4.5 untuk mengklasifikasikan tingkat pengetahuan masyarakat terhadap pemanfaatan bank sampah di kabupaten Banjarmasin selatan untuk mengetahui hasil dari keakuratan data.

\section{HASIL DAN PEMBAHASAN}

Setelah Proses pengumpulan data selesai, selanjutnya proses data dilakukan dengan menggunakan Rapidminer.

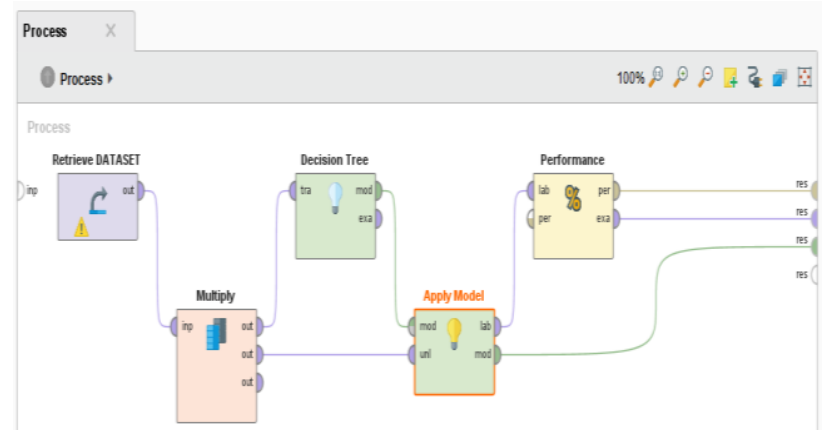

Gambar 1. Proses Data Menggunakan Rapid Miner

Selanjutnya, berdasarkan hasil proses evaluasi model untuk decision Tree dengan kriteria information gain diperoleh pohon Keputusan seperti gambar berikut.

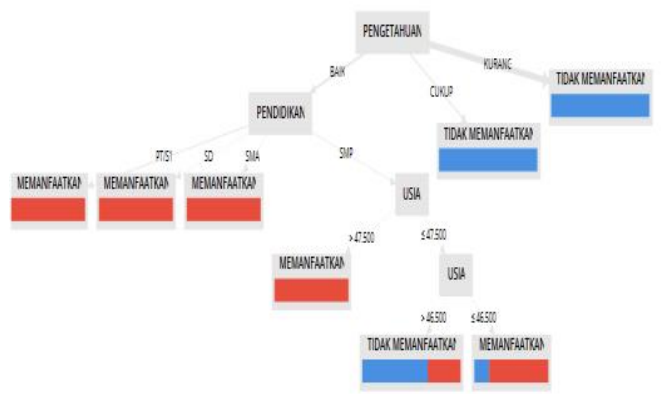

Gambar 2. Hasil implementasi Berupa

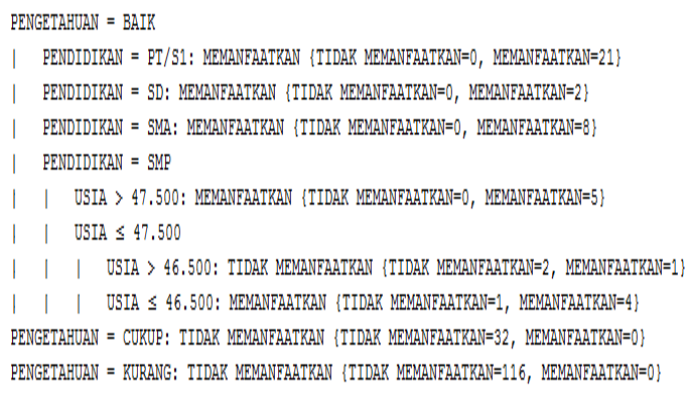

\section{Pohon Keputusan}

Pada Pohon Keputusan ini menghasilkan aturan atau rule yang akan 
Tabel 2. Penjelasan Pohon Keputusan

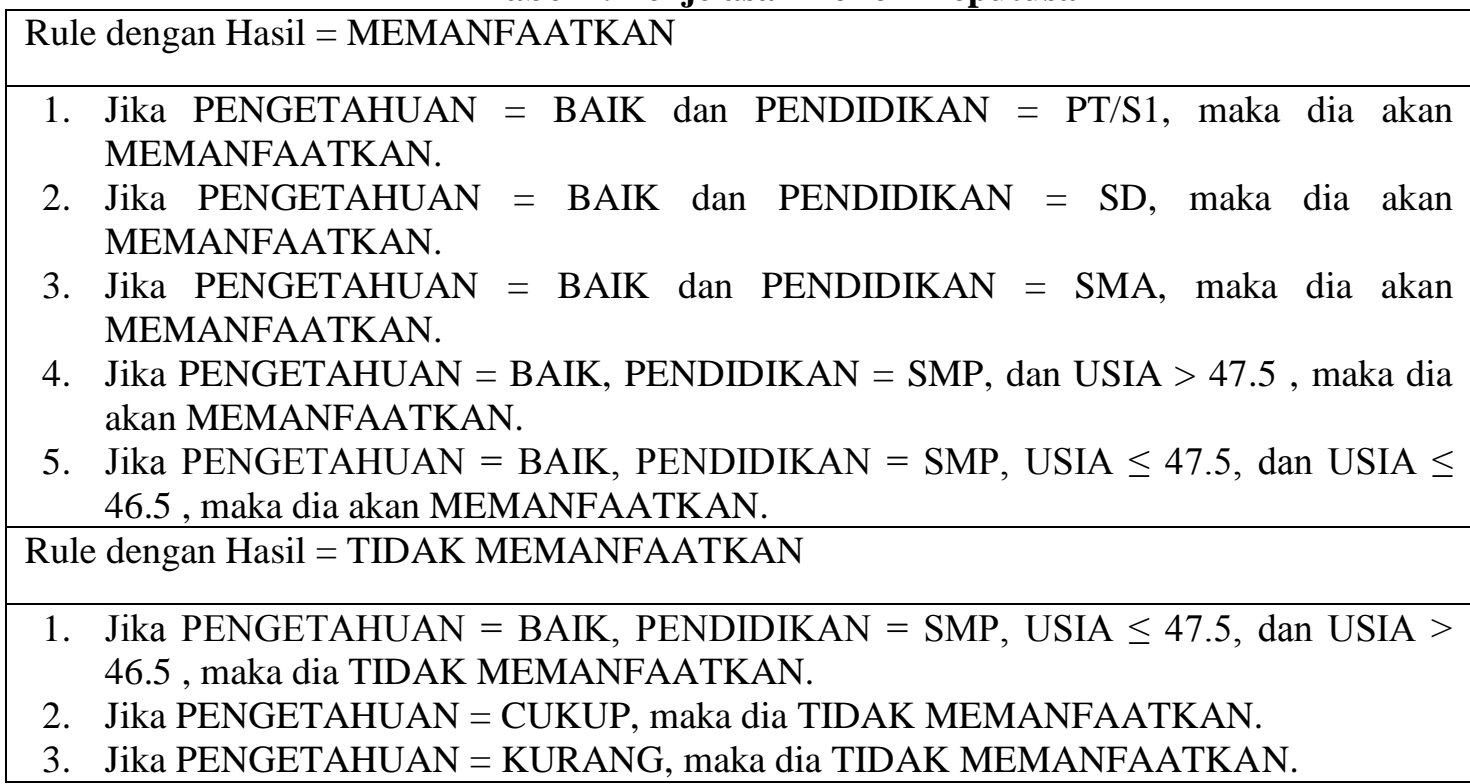

Dari hasil pohon keputusan pada proses Evaluasi Model ini diperoleh prediksi sebagai berikut:

Tabel 3. Hasil nilai performance model pada proses Evaluasi Model.

\begin{tabular}{|l|c|c|c|}
\hline & \multicolumn{2}{|c|}{ Actual } & class \\
\cline { 2 - 4 } precision & $\begin{array}{l}\text { TIDAK MEMANFAATKAN } \\
\text { (Negative) }\end{array}$ & $\begin{array}{l}\text { MEMANFAATKAN } \\
\text { (Positive) }\end{array}$ & $99.34 \%$ \\
\hline $\begin{array}{l}\text { TIDAK MEMANFAATKAN } \\
\text { (False) }\end{array}$ & 150 & 1 & $97.56 \%$ \\
\hline $\begin{array}{l}\text { MEMANFAATKAN } \\
\text { (True) }\end{array}$ & 1 & 40 & \\
\hline class recall & 99.34 & 97.56 & \\
\hline
\end{tabular}

Nilai accuracy sebesar $98.96 \%$ dihitung dengan cara membagi jumlah dari banyaknya data True Positif (TP) dan banyaknya data False Negatif (FN) dengan jumlah keseluruhan.

$$
\begin{aligned}
& \text { accuracy }=\frac{T P+F N}{T P+T N+F P+F N} * 100 \% \\
& \text { accuracy }=\frac{40+150}{40+1+1+150} * 100 \%=98.96 \%
\end{aligned}
$$

Nilai precision untuk TIDAK MEMANFAATKAN dihitung dengan cara membagi banyaknya data False Negative (FN) dengan jumlah dari banyaknya data False Negative (FN) dan banyaknya data False Positive (FP).

$$
\text { precision }=\frac{F N}{F N+F P} * 100 \%
$$

$$
\begin{array}{ll}
\text { precision } & =\frac{150}{150+1} * 100 \% \\
\text { Nilai } & =99.34 \% \\
\text { precision } & \text { untuk }
\end{array}
$$
MEMANFAATKAN dihitung dengan cara membagi banyaknya data True Positif (TP) dengan jumlah dari banyaknya data True Negatif (TN) dan banyaknya data True Positif (TP).

$$
\begin{aligned}
& \text { precision }=\frac{T P}{T N+T P} * 100 \% \\
& \text { precision }=\frac{40}{1+40} * 100 \%=97.56 \%
\end{aligned}
$$

Nilai recall untuk TIDAK MEMANFAATKAN dihitung dengan cara membagi banyaknya data False Negative (FN) dengan jumlah dari banyaknya data True Negative (FN) dan banyaknya data True Negative (TN). 


$$
\begin{aligned}
\text { recall } & =\frac{F N}{F N+T N} * 100 \% \\
\text { recall } & =\frac{150}{150+1} * 100 \%=99.34 \%
\end{aligned}
$$

Nilai recall untuk MEMANFAATKAN dihitung dengan cara membagi banyaknya data banyaknya data False Negatif (FP) dan banyaknya data True Positif (TP).

$$
\begin{aligned}
& \text { recall }=\frac{T P}{F P+T P} * 100 \% \\
& \quad r e c a l l=\frac{40}{1+40} * 100 \%=97.56 \%
\end{aligned}
$$

Dari Evaluasi Model, diperoleh nilai performance model yang sangat baik untuk nilai accuracy, precision, dan recall.

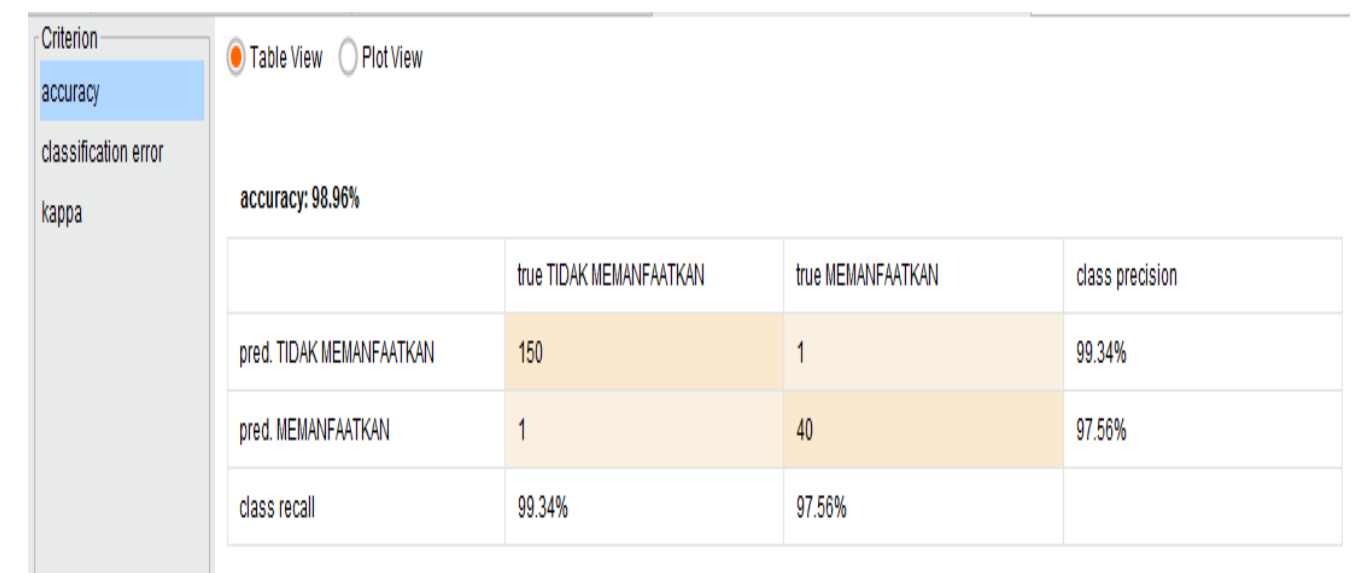

Gambar 3. Hasil Akurasi

\section{KESIMPULAN}

Berdasarkan pada tahap Pengujian yang dilakukan dari awal sampai akhir dari segi Pengetahuan, Pendidikan dan Usia maka di simpulkan bahwa: Pengetahuan Bank Sampah pada masyarakat Kelurahan Pemurus Baru Kecamatan Banjarmasin Selatan kota Banjarmasin Tidak memanfaatkan Bank sampah dengan nilai akurasi $99.34 \%$ sehingga perlu di tingkatkan lagi sosialisasi terhadap masyarakat untuk bisa memanfaatkan bank sampah dengan baik.

\section{REFERENSI}

[1] R. P. Mahyudin, "Kajian permasalahan pengelolaan sampah dan dampak lingkungan di TPA (Tempat Pemrosesan Akhir)," Jukung (Jurnal Tek. Lingkungan), vol. 3, no. 1, pp. 66-74, 2017.

[2] R. Damayanti and S. Susilih, "Efektivitas Pengelolaan Sampah melalui Bank Sampah (Studi tentang Bank Sampah di Kecamatan Sukmajaya. Depok)," J. Ilmu Sos. dan Ilmu Polit., vol. 1, pp. 1-17, 2014.

[3] A. D. E. WULANDARI, "Kepemimpinan dan Partisipasi Masyarakat dalam Program Bank Sampah," Stud. Pustaka, vol. 3, no. 4, 2016.

[4]Kartini. 2009. "Faktor-Faktor Yang Mempengaruhi Keputusan Masyarakat Menabung Sampah Serta Dampak Keberadaan Bank Sampah Gemah Ripah"

[5] Kementrian Lingkungan Hidup Republik Indonesia. 2012, Pedoman 3R Melalui Bank Sampah, Jakarta.

[6] Damhuri, E., Padmi, T. 2011, Pengelolaan Sampah, Diklat Kuliah TL-3104, Institut Teknologi Bandung, Bandung.

[7] Saputra, J, M, C. 2007, "Pengaruh Sikap dan Tingkat Pendidikan Terhadap Partisipasi Masyarakat Dalam Pengelolaan Sampah di Sepanjang Jalan Mukharjo Raya, Skripsi, Universitas Diponegoro, Kota Semarang".

[8] Ian H., W., \&amp; Frank, E. (2005). "Data Mining: Practical Machine Learning Tools and Techniques (2 ed.). San Francisco: Morgan Kaufmann Publishers is an imprint of Elsevier". 
[9] Larose. (2006). Data Mining Methods And Models. Canada: John Wiley \&amp; Sons, Inc.

[10] Karyadiputra, E, Hijriana, N.(2019). Penerapan Algoritma Decision Tree C4.5 Untuk Klasifikasi Penentuan Daftar Prioritas Pengembangan Jembatan: Jurnal Ilmiah Technologi, 10,(1) : 43-46 